\title{
The Inclusiveness and Emptiness of Gong Qi: A Non-Anglophone Perspective on Ethics from a Sino-Japanese Corporation
}

\author{
Wenjin Dai ${ }^{1}\left[\right.$ ] Jonathan Gosling ${ }^{2} \cdot$ Annie Pye $^{3}$
}

Received: 18 August 2017 / Accepted: 5 October 2019 / Published online: 22 October 2019

(c) The Author(s) 2019

\begin{abstract}
This article introduces a non-Anglophone concept of gong qi (communal vessel, 公器) as a metaphor for 'corporation'. It contributes an endogenous perspective from a Sino-Japanese organizational context that enriches mainstream business ethics literature, otherwise heavily reliant on Western traditions. We translate the multi-layered meanings of gong qi based on analysis of its ideograms, its references into classical philosophies, and contemporary application in this Japanese multinational corporation in China. Gong qi contributes a perspective that sees a corporation as an inclusive and virtuous social entity, and also addresses the elusive, implicit, and forever evolving nature of organizational life that is rarely noticed. We propose gong qi can be applied in other organizations and wider cultural contexts to show a new way of seeing and understanding business ethics and organization. Rather than considering virtue as a list of definable individual qualities, we suggest that the metaphor of gong qi reveals how virtue can be experienced as indeterminate, yet immanently present, like the substance of emptiness. This, then allows us to see the virtue of immanence, the beauty of implicitness, and hence, the efficacy of gong qi.
\end{abstract}

Keywords Ethics $\cdot$ Virtue $\cdot$ Gong qi $\cdot$ CSR $\cdot$ Non-Western $\cdot$ Chinese $\cdot$ Japanese

\section{Introduction}

It has been realized that business ethics and management may not everywhere be interpreted and experienced the way it is defined by Western-inspired models in the English language (e.g. Todeschini 2011; Wang and Juslin 2009). Although there are commonalities and shared understanding between the so-called 'Eastern' and 'Western' perspectives on business ethics (Koehn 2013; Yu 1998), it is increasingly recognized that many Eastern, Southern and other non-Anglophone contexts have distinctive features and

Wenjin Dai

Wenjin.Dai@open.ac.uk

Jonathan Gosling

Jonathan.Gosling@exeter.ac.uk

Annie Pye

PyeAJ@cardiff.ac.uk

1 Department of Public Leadership and Social Enterprise, The Open University Business School, Walton Hall, Milton Keynes MK7 6AA, UK

2 University of Exeter Business School, Exeter EX4 4PU, UK

3 Cardiff Business School, Cardiff University, Cardiff CF10 3EU, UK perceptions due to deeply embedded philosophical traditions and cultural values (Chun 2005; Hennig 2016; Karam and Jamali 2017; Todeschini 2011; Xu and Yang 2010).

The difference between 'Eastern' and 'Western' thinking is considered rather fundamental due to linguistic differences: in non-alphabetic languages like Chinese, meaning is never literal nor unambiguous as language is seen as inadequate to capture the perpetually changing and complex realities (Chia 2003; Jullien 2004). Hence, meanings are gradually understood in relation to specific contexts and situations, rather than pre-fixed by clear definitions, as assumed in most contemporary Western thinking. Chia and Holt (2009) propose that this is associated with dispersed and indirect action, which has a surprising efficacy that can lead to collective social good and organizational accomplishments, without deliberate, pre-determined and well-articulated plans. Although the difference between the so-called 'East' and 'West' should not be seen as a fixed demarcation based on geographical sites (Dai 2018), it is necessary that people used to either ways of thinking develop mutual understanding of these alternative conceptualizations in order to comprehend business ethics and management in the increasingly globalized world. Rather than drawing on the over-simplified Western/Eastern dichotomy, we recognize 
the impetus of different philosophical traditions, and focus on the contribution of the specific endogenous ${ }^{1}$ concept of gong qi.

Despite growing research interest in the field, there is a lack of empirical studies that demonstrate the usefulness of endogenous concepts from non-Anglophone organizational contexts in understanding the paradoxical and complex nature of organization and ethics (Chia 2003; Tsui 2009; Yin and Quazi 2018). Scholars are urged to "actively engage with grassroots meaning-making" and "decipher and strengthen alternative systems of organizing" to re-define business ethical concepts (Mitra 2012, p. 132). Hence, there is a growing need for contextually based and culturally tailored theory-building in business ethics research (Alzola et al. 2017; Mitra 2012; Todeschini 2011; Yin and Quazi 2018). This article contributes to this effort.

China's crucial and highly influential role in the world economy implies that in-depth studies of the understanding and meanings of business ethics from Chinese contexts are significant both locally and globally. To gain such an appreciation of meanings, a qualitative, particularly an ethnographic approach is useful to develop an understanding of the ways in which ethics and virtue are practiced and experienced through everyday language and relationships. We developed an ethnographic account grounded in the Chinese subsidiary of a Japanese Multinational Corporation (which we refer to as SONA). We noticed frequent and significant use of an endogenous term gong qi (公器, which we render as Communal Vessel) promoted within its corporate philosophy. Nevertheless, we have to address the paradoxical nature of explicating such an endogenous term as this article is written in English, transcripts had to be translated into English, and the culturally embedded connotations of the term gong $q i$ are reduced in its translation as 'Communal Vessel'.

Through exploring the classical roots of multi-layered meanings of gong $q i$ and how this concept operates in this

\footnotetext{
1 The indigenous and endogenous frameworks from cross-cultural studies have often been used to analyze business ethics notions and expressions when comparing global with local contexts (Jackson 2014; Karam and Jamali 2017). Indigenous research has attracted much scholarly interest in organization studies, and many employ this concept to create indigenous theories and knowledge as distinguished from so-called 'Western' knowledge; yet the term 'indigenous' is mostly used without much explanation or definition (Dei 1993; Jackson 2013). The overuse and misuse of 'indigenous knowledge' in cross-cultural research has been criticized for confusing two notions of indigenousness, one rooted in colonialism and another in globalization (Briggs, 2005; Jackson, 2013). The term 'endogenous' is thereafter proposed to offer a less controversial approach to refer to specific characteristics, values, ideas, knowledge, institutions and practices that emerge from a society or organization (such as guanxi) (Jackson 2013; Maruyama 1981; Schuler et al. 1993). Hence, this article takes an endogenous approach as a way of exploring a socalled 'Eastern' understanding of ethics in the context of China.
}

Sino-Japanese corporate context, this article contributes to a non-Anglophone perspective of understanding ethics and organization. Gong qi offers a unique insight that not only reveals a corporation as an inclusive and virtuous social entity, but also addresses an elusive, implicit, and forever evolving quality of organizational life that is rarely noticed.

The following sections proceed thus: First, we introduce the suggested meanings of gong qi (公器), and review extant literature on the differences between Eastern and Western thinking in understanding ethics and organizations, as well as examining some previous studies in Chinese and Japanese contexts. Second, the research methods, fieldwork setting, and analytical process will be explained. Third, we present the multi-layered meanings of gong $q i$ and how it functions in organizing virtue at the organization. From this, we draw out the ethical aspects and virtues suggested by gong $q i$ and show how these influence policies and practices in the organization. We conclude that as an endogenous conception, gong qi has important theoretical and empirical implications for widening our understanding towards ethics and organizations.

\section{Gong Qi: An Endogenous Metaphor for a Virtuous Corporation}

Morgan (1986, 2016) and many others argue persuasively that metaphor plays a formative role in everyday thinking, and in organization studies new metaphors help to generate new ways of understanding, particularly revealing the complex and semantically constructed nature of what counts as organizational realities. A metaphor proceeds through assertions that A is (or is like) B. In SONA's corporate philosophy statement we read "a corporation is society's gong qi". Gong qi is here used as a metaphor for corporation, suggesting a way of thinking about what a corporation should be in relation to society.

The meaning of gong qi is multi-layered and deeply rooted in classical philosophies and ideograms which will be discussed in greater detail in a later section. However, to simplify this here, the meanings of gong qi originate in reference to a sacrificial vessel in ancient Chinese ritual ceremonies, containing offerings to gods and ancestors. It is often used as a metaphor which represents people with virtuous characters and great capabilities, as well as symbolizing public goods that are shared with others, that are unobtainable, uncontrollable, yet can be used to act and govern for the common good.

Gong qi expresses virtue in a way that means doing good for the community, sharing with others, acting with righteousness and so on; yet, it also includes being empty with the potential to be filled, implying an ambiguity about its actual contents and functions. Its significance as being 
implicit rather than confined, and eventually being useful but not possessed. When gong qi is used as a sacrificial vessel, its function is to reach beyond human manipulation; thus being in total control of gong qi is nothing but one's fantasy. Virtue is fundamentally inherent to gong qi. As an endogenous metaphor for the virtue of corporations, it expresses the understanding that a corporation is an inclusive and virtuous social entity to serve the common good. Gong qi also suggests aspects of virtue that are more elusive, implicit, and culturally immanent, which are praised in classical Chinese and Japanese thinking.

It is often recognized that modern Chinese and Japanese conceptions of virtue and ethics derive from classical philosophies, such as Confucianism and Daoism (e.g. Du 2015; Hennig 2016; Lin et al. 2013; Lu 1997; Romar 2002; Wang and Juslin 2009), and some celebrate a so-called 'cultural renaissance' of traditional values around the world (Wang and Lin 2009). More pertinently, these traditional philosophies influence ways of thinking and how people make sense of organizational practices today (Du 2015; Ma and Tsui 2015; Romar 2002). For instance, some scholars argue that classical philosophies such as Confucianism and Daoism commit to an ontology in which flux and constant change are the principles of life (Chia 2003; Hofstede and Bond 1988; Low and Ang 2012). This, it is claimed, constructs distinctive understandings of virtue and ethics in contemporary organizations and organizing processes.

The commonalities and differences between Eastern and Western ways of thinking have been debated for decades, particularly regarding their understandings of virtue ethics. Confucian virtue ethics is claimed to be similar to the Aristotelian conception, by comparing Confucius' ren (仁) with Aristotelian $a r e t \bar{e}$, which share similar connotations of being noble and humane (Koehn 2016). In extant Western-inspired literature, virtue ethics generally focus on "being good as a person" (Alzola 2015, p. 301). This is sometimes extended to an organization as if it were a person, able to act in more or less virtuous ways. As Koehn writes (2016, p. 273), “for Confucius, as for Aristotle, virtue is something that can be perceived. We can hear and see virtue (or vice) in action by attending to what our fellow family members, friends, citizens, colleagues and politicians do and say and how they bear themselves". However, some Confucian ethicists believe virtue is not an individually accomplished collection of good qualities as emphasized by Aristotle. Instead, virtue is about how we attend to the relationships and responsibilities that simultaneously constitute us (Ames and Rosemont 1998; Santiago 2008; Yu 1998). To grasp the Eastern way of thinking one must understand that virtue is essential to all aspects of relationship. A Confucian concept of becoming human is through self-cultivation, which is a fundamentally social process rather than an individual journey of personal development (Tu 1998). Being a virtuous human is achieved through the enactment of $l i$ (礼), often translated as etiquette, rites, and rituals. Rendered as 'observing ritual propriety' by Ames and Rosemont (1998), the concept of $l i$ has a strong emphasis on social order and relationality. On these grounds Romar (2002) argues that Confucianism is a compelling basis for organizational ethics as it is compatible with modern managerial practices. Although Confucianism originated from the unsettled Warring States period (770-221 BCE), its influence continues to this day throughout China, Japan, Korea, Singapore, and other parts of East Asia.

Japan shares a similar cultural heritage (Lockett 1988), and its ethical and managerial philosophies are much influenced by Confucian traditions along with so-called Japanese divergent Confucianism (Boardman and Kato 2003; Chan 2008; Ornatowski 1999). Indeed, Japan is an evolving society that is influenced by Western scientific management as much as Confucianism, Buddhism, and Shintoism. This is expressed in one of Japan's most famous slogans from the Meiji Restoration, 'Eastern ethics, Western science' (Dollinger 1988; Kimura and Nishikawa 2018). Although the bursting of the 'bubble economy' reduced some Western fascination towards Japanese business practices, understanding different ways of thinking and ethical practices of Japanese corporations and their overseas subsidiaries remains highly relevant for business ethicists (Acquier et al. 2018; Endo et al. 2015; Kimura and Nishikawa 2018).

Most studies and interpretations of so-called 'Eastern' ethics and virtue are based only on Confucianism (Koehn 2016; Yu 1998), yet it represents just one stream of the 'hundred schools of thought' developed during the Warring States period (770-221 BCE). Daoism has different claims and arguments compared to Confucianism. Rather than promoting articulated virtues and moral ideals, Daoist virtues "highlight the alignment between the human being and Nature through following the Way of Nature" (Hennig 2016, p. 572). Rendering $D e$ (德) as virtue, we find the first chapter in the Book of De (Chapter 38 in Dao De Jing, translated by $\mathrm{Gu}, \mathrm{Z}$.) claims that "A man of great virtue does not claim to be of virtue, thus he is of the true virtue... a man of the great virtue remains inactive, without deliberately manifesting his [or her] virtue" (Lao-Tzu(老子) 2008 [c. 500 BCE], p. 107). Compared to the value that Confucianism places on accruing virtues, Daoism decries the categorization and claiming of virtue, so a 'virtuous self' is already a departure from virtue. Both Confucian and Daoist perspectives will be discussed later in relation to gong qi.

Koehn (2013) argues that virtue is part of the human experience with a natural basis and a structure that seems to be transcultural. Thus, it is particularly interesting to develop an understanding of how the concept of gong qi (公器) is interpreted and experienced in a Japanese MNC based in China, and the potential implications to wider contexts. We do not intend to make a generalization to all Chinese or 
Asian corporations, but through a hermeneutic process of iterative interpretations, we reveal the both embracive and elusive aspects of gong qi that gesture towards the indeterminant and complex nature of organizational realities.

\section{Methodology}

A constructionist and qualitative approach (Berger and Luckmann 1966) is adopted in this study which explores an endogenous understanding of the meanings, policies and practices associated with the term gong $q i$ which came to light through our research into Corporate Social Responsibility (CSR) in this corporate context. In particular, ethnography is employed as a creative, exploratory and interpretive process to analyze social life and meanings (Humphreys et al. 2003; Watson 2011). A full-time working role as an intern was negotiated within an organization (in China) which offered the opportunity to conduct in-depth interviews and close observation. We call this organization 'SONA'. The manager of the Corporate Culture Department agreed (on behalf of SONA China) to grant research access, in return for which the first author worked there as a Corporate Culture Intern for 3 months. With the opportunity this job role permitted, we could recruit interview participants from various levels of the organization: from the CEO, department managers to first line workers.

The data source includes 17 semi-structured interviews of 1-3 h duration, company documents such as internal magazines and posters, and 40,000 words of field notes based on the 3 months' work experience in the Corporate Culture Department. Sixteen interviews were recorded and fully transcribed in Chinese. Every passage of the interview transcripts was analyzed and coded. The key codes relating to characters, events, plots, and everyday artifacts were systematically analyzed using thematic analysis. Reading all interview transcripts and field notes, we picked up common patterns as they evolved from this process of thematic interpretation, and thus sought to avoid predefining participants' experiences (McAuley 2004). In this article we focus on the narrative construction of gong qi, which was the focus of its corporate philosophy.

Via this 'enhanced ethnography', the act of writing and rewriting is used as an interpreting process that continually makes sense of stories, events, and plots (Humphreys and Watson 2009; Ybema et al. 2009). Field notes were written in a detailed, open and reflective way, such as stories and reflections from others along with those of the first author to encourage emerging and nuanced understanding. We believe the combination of observational method and qualitative interviewing improves the validity of the findings, and adds rigor, depth, breadth and richness to this inquiry (Denzin and Lincoln 2005; Flick 2002).

\section{Focus Organization}

SONA is a Japanese Multinational Corporation (MNC), a well-known, global manufacturer of electronic products with a 100-year history. It has developed a 'SONA Corporate Philosophy System' (企业理念) which advocates service for society and achieving excellence in its practices. This is promoted in every SONA subsidiary across the world including SONA China. In recent years, SONA China has achieved a series of international environment benchmarks, and has been publicly recognized as one of the most socially responsible MNCs in China. SONA's Corporate Philosophy was considered to be so important for daily practices that a new department called the 'Corporate Culture Department' had been established. During the internship, the first author was immersed in the corporate culture, and was often charged with promoting it to other employees across several subsidiaries of SONA in China.

In the next section, the findings will be presented as they offer representative and allegorical examples of how the meanings of gong qi emerged and how it functions in organizing virtue in SONA. This research is not looking for the "one correct telling" (Denzin and Lincoln 2005, p. 6) rather, each telling reflects a different perspective, offering more understanding in a fluid and continuous process; more filaments to the web of meaning.

\section{The Meanings of Gong Qi}

Like other endogenous ideas (e.g. harmony and guanxi) from classical Chinese literature, gong qi could have important implications for management theory and practice in China, and beyond (Li et al. 2012; McElhatton and Jackson 2012). As a metaphor from classical literature, gong qi influences the way people think about virtue and organization across different contexts. Thus, we start by examining the rich meanings represented in Chinese ideograms of these two characters 公 (gong) and 器 (qi) (see Fig. 1), and some of their philosophical roots.

\section{The Ideograms of Gong Qi}

Unlike alphabetic languages such as English, Chinese language is written in ideograms, in which both drawn image and written text imply meanings. 'A picture paints a thousand words', and ideogrammatic languages have the ability of representing complex ideas in a simple way, but often ambiguously as meaning goes beyond the literal and is interpreted in the context of specific situations (Chia 2003; Ong 
Fig. 1 The analysis of gong qi (公器)'s ideograms (Bronze Inscriptions). Bronze Inscriptions (金文jin wen) are shown here as this type of characters were used during the Warring States period (770-221 BCE), when these classical Chinese philosophies were written. They are called 'Bronze Inscriptions' as these characters used to be inscribed on bronzeware
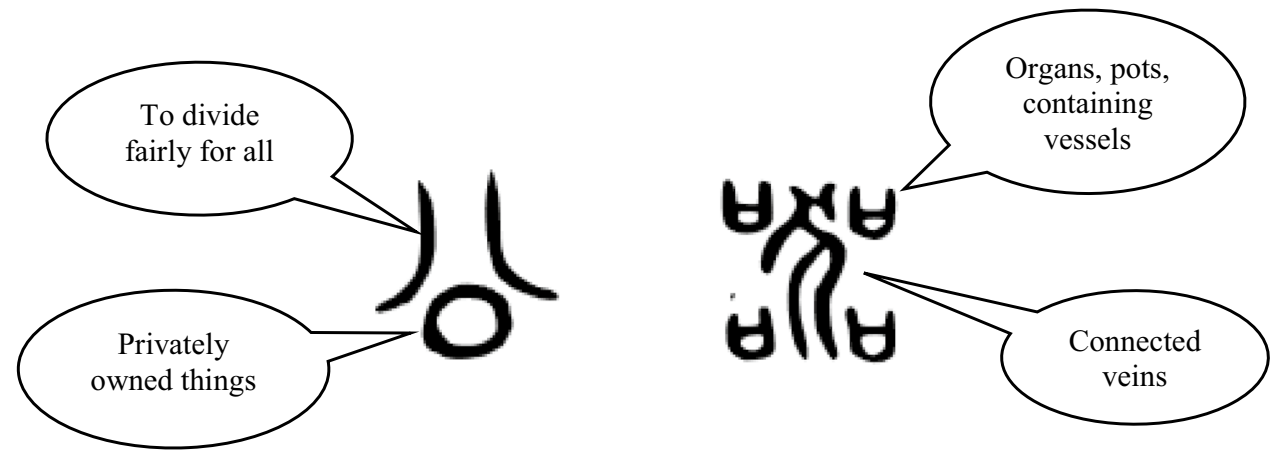

1967). Hence the context becomes crucial in grasping the meanings of characters, which often have multiple possible interpretations and pronunciations. The sentences where the characters appear, the classical literature where those sentences originate, and the ideas of authors all need to be considered. This follows a hermeneutic process of iterative interpretation between pre-understanding and understanding (see McAuley 2004). Therefore, our analysis of the multilayered meanings of gong qi combines examinations of the ideograms (Fig. 1), original quotes from the classics, and their translations (Table 1).

The analysis of the ideograms is based on 'Shuo Wen Jie Zi' (《说文解字》) (Xu and Tang 2018 [100-121 CE]), a classical Chinese dictionary from the Han Dynasty. Figure 1 shows, the character 公 (gong) has two parts: the lower half ' $\Delta$ ' symbolizes foods or goods that are privately owned, and the upper half '八' implies the action of dividing these foods and goods fairly to be shared in a community. The character 器 ( $q i)$ is composed by four ' $\square$ ' at the corners depicting utensils that contain food or wine, and intertwined veins (犬) in the middle connecting and looking after these containing vessels.

\section{The Philosophical Roots of Gong Qi}

The characters qi (器) and gong qi (公器) are found in Chinese classical literature, such as The Analects of Confucius (translated by Lau, D. C.), Daodejing (translated by $\mathrm{Gu}$, Z.), and Mengzi (translated by Legge, J.). Qi (器) is considered the key word in the term gong qi, as sometimes it was used alone in the literature rather than together with gong. Hence both qi, and gong qi need to be examined in order to capture the philosophical meanings of gong $q i$, and the resonance of these meanings in modern usage. Due to the unavailability of reliable English versions, the first author translated the quotes based on careful study of the original Chinese prose and use of appropriate classical dictionaries and commentaries.

In Table 1, the usages of gong qi are collated and presented from the more concrete to more abstract meanings (an alternative ordering would emphasize differences between more active and passive).

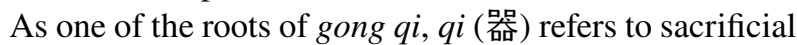
vessels being used in ritual ceremonies. In the ancient rituals (礼, $l i$ ) which represent the highest social order in China, these special vessels were used to contain grain or wine for offering to gods and ancestors, as described in Mengzi (Book 10, Wan Zhang Part 2) in Table 1. Those vessels were often inscribed with accounts of historical events and naming generation after generation. Hence, a sacrificial vessel here allegorically indicates a moral ideal with virtuous qualities that were valued across generations. Such a vessel could be a delicate bowl made of jade or gold, though in national ceremonies they tended to be large, heavy bronzeware with three or four legs, and were carried by a group of people.

Similar uses of qi have appeared in The Analects of Confucius (Book 5) and Daodejing (Chapter 41) as shown in Table 1. Referring to a sacrificial vessel, qi has also been used as a metaphor for people with great capabilities and qualities that are useful for society. To say someone (for example Zigong, as one of the foremost students of Confucius) is like a sacrificial vessel, implies that person has capabilities and virtuous characteristics that are admirable not just in society but through generations. $Q i$, here, can be used as a verb too: as in, to choose and promote people based on their capabilities and virtues that express treasured values (Ames and Rosemont 1998; Confucius 1979 [c. 500-400 $\mathrm{BCE}])$.

$Q i$ is also used as a metaphor by Zhuangzi (in Chapter Tianyun, approx, 350-250 BCE), referring to aspects of our world that cannot be truly obtained by anyone. These classical Chinese philosophies were mostly written during the Warring States period (770-221 BCE) when there were continuous wars among five to seven separate kingdoms, with forceful attempts to unify and thereby to 'obtain' the world. Laozi (or Lao-Tzu) (2008 [c. 500 BCE]), here, used $q i$, as a metaphor to symbolize how sacred the world is, and it should never be seen as an object at people's disposal. This use of $q i$ also reveals the nuanced differences between Confucianism and Daoism: while Confucius emphasizes the importance of virtuous qualities and moral ideals in society, 
Table 1 Meanings of gong $q i$

\begin{tabular}{|c|c|c|}
\hline Meanings of gong qi & Classical references & Original quotes and translations \\
\hline $\begin{array}{l}\text { Sacrificial vessel used in ritual cer- } \\
\text { emonies }\end{array}$ & $\begin{array}{l}\text { 孟子万章下,卷十 } \\
\text { Mengzi, Book 10, Wan Zhang, Part } 2\end{array}$ & $\begin{array}{l}\text { 孔子先簿正祭器,不以四方之食供簿正 } \\
\text { Confucius first rectified the registers to offer sacrificial ves- } \\
\text { sels, so he did not (have to) fill the vessels with precious } \\
\text { food from everywhere to match with the registers }\end{array}$ \\
\hline \multirow[t]{2}{*}{$\begin{array}{l}\text { Sacrificial vessel (also refers to people } \\
\text { with great capabilities that are useful } \\
\text { for society) }\end{array}$} & $\begin{array}{l}\text { 论语, 公治长篇第五 } \\
\text { The Analects of Confucius, Book } 5\end{array}$ & $\begin{array}{l}\text { 子贡问曰:“赐也何如?”子曰:“汝器也。”曰:“何器也?” } \\
\text { 曰:“琏瑚也。” } \\
\text { Zigong asked, “what do you think of me?” The Master } \\
\text { said, “You are a qi (vessel)”. “What kind of qi (vessel)?” } \\
\text { "A sacrificial vessel made of jade.” }\end{array}$ \\
\hline & 道德经,第41章Daodejing, Chapter 41 & $\begin{array}{l}\text { 大方无隅, 大器晚成, 大音希声, 大象无形。 } \\
\text { The great square has no corners, the most precious vessel } \\
\text { takes the longest time to be finished (rarely completes), } \\
\text { the great sound seems soundless, and the great image has } \\
\text { no form }\end{array}$ \\
\hline $\begin{array}{l}\text { Sacrificial vessel (also refers to the } \\
\text { world that cannot be truly obtained } \\
\text { by anyone) }\end{array}$ & $\begin{array}{l}\text { 道德经,第29章 } \\
\text { Daodejing, Chapter } 29\end{array}$ & $\begin{array}{l}\text { 天下神器,不可为也,为者败之,执者失之。 } \\
\text { The world is a sacred vessel that cannot be obtained; those } \\
\text { who try to obtain it will fail, those who try to keep it will } \\
\text { lose it }\end{array}$ \\
\hline \multirow[t]{3}{*}{ Public goods } & $\begin{array}{l}\text { 庄子, 外篇, 天运 } \\
\text { Zhuangzi, Chapter Tianyun }\end{array}$ & $\begin{array}{l}\text { 名,公器也,不可多取。 } \\
\text { Fame is a gong qi (public goods), do not get much }\end{array}$ \\
\hline & $\begin{array}{l}\text { 白居易,感兴二首 } \\
\text { Baijuyi (Tang Dynasty), Poem }\end{array}$ & $\begin{array}{l}\text { 名为公器无多取,利是身灾合少求。 } \\
\text { Fame and money are gong qi, do not get too much other- } \\
\text { wise disaster might follow }\end{array}$ \\
\hline & $\begin{array}{l}\text { 陆游, 喜杨廷秀秘监再入馆 } \\
\text { Luyou (Song Dynasty), Poem }\end{array}$ & $\begin{array}{l}\text { 文章实公器,当与天下共。 } \\
\text { Literature and knowledge are indeed gong qi, should be } \\
\text { shared with the world }\end{array}$ \\
\hline \multirow[t]{2}{*}{ Virtue } & $\begin{array}{l}\text { 墨子,十二卷,公孟 } \\
\text { Mozi, Book 12, Gong Meng }\end{array}$ & $\begin{array}{l}\text { 夫义,天下之大器也,何以视人必强为之? } \\
\text { Righteousness is the greatest qi (virtue) in the world, no } \\
\text { need to look at others, (we) must try practising it (our- } \\
\text { selves) }\end{array}$ \\
\hline & $\begin{array}{l}\text { 䊩子, 卷下, 道符 } \\
\text { Yuzi, Part 2, Dao Fu }\end{array}$ & $\begin{array}{l}\text { 仁与信, 和与道, 帝王之器。 } \\
\text { Humanity, trustworthiness, harmony and Dao, those are the } \\
\text { qi (virtues) of being a king }\end{array}$ \\
\hline $\begin{array}{l}\text { Things that can be used to act and } \\
\text { govern }\end{array}$ & 道德经, 第28章Daodejing, Chapter 28 & $\begin{array}{l}\text { 朴散则为器, 圣人用之, 则为官长, 故大制不割。 } \\
\text { When simplicity is dispersed (as if the material is being } \\
\text { sharpened), the material becomes qi. If the Sages use it, } \\
\text { they can govern and lead the others. Hence great govern- } \\
\text { ance cannot be separated (from Dao) }\end{array}$ \\
\hline
\end{tabular}

Daoism sees virtue as ontologically prior to society, identifying it with nature independently of human instrumental interests.

Based on the analysis of gong qi's ideograms, the term gong $q i$ is often seen in classical literature as referring to public goods that do not actually belong to individuals. Rather, they should be shared by the community and society, such as fame, money, literature and knowledge.

Virtue is inherently embedded in the term of gong $q i$, such that the character $q i$ can also be interpreted as virtue. As often the sacrificial vessels were made of precious materials such as jade, qi metaphorically symbolizes things that are valued and praised in society, for instance virtue. Based on a Confucian conception of qi, Mozi and Yuzi specified what those virtues could be. For instance,
Mozi (Book 12, Gong Meng) argued that righteousness is the greatest $q i$ (virtue) in the world. Yuzi (Part 2, Dao Fu) claimed the virtues (qi) of being a king are ren (humanity), xin (trustworthiness), he (harmony), and Dao (the way). Righteousness is often recognized in contemporary Japanese corporate philosophies, which can be traced to the influence of bushido (rendered as 'the warrior's way'), the samurai's ethical code emphasizing a strong sense of loyalty and dedication towards society (see Dollinger 1988). However, the virtues suggested by $q i$ are not entirely conceived as individual traits in the manner of Aristotelian virtues; they instead describe the nexus of social/individual without separating one from the other. One cannot simply exercise, for example, humanity (仁ren) without attending to the social relationships, responsibilities and 
Table 2 How virtues suggested by gong $q i$ influence policies and practices at SONA

\begin{tabular}{|c|c|c|}
\hline Virtues of gong qi & Practices of gong $q i$ at SONA & Exemplar quotes \\
\hline 1. Being useful for society & Providing good products to solve social problems & $\begin{array}{l}\text { "It's not just returning profit to society, but it's also } \\
\text { about facing and solving the current problems } \\
\text { within that society. That is one of the functions of } \\
\text { gong qi." [the CEO] }\end{array}$ \\
\hline 2. To share with others & $\begin{array}{l}\text { Contributing to society, sharing interests with the } \\
\text { community }\end{array}$ & $\begin{array}{l}\text { "The social part of gong qi is about sharing interests, } \\
\text { such as paying tax, making donations, and having } \\
\text { CSR events. It is about contributing to society." } \\
\text { [HR Director] }\end{array}$ \\
\hline 3. Righteousness & To behave righteously & $\begin{array}{l}\text { "We will be righteous, do good things, and go } \\
\text { towards the right direction. No matter what we } \\
\text { produce, and what kind of influence we bring to } \\
\text { society, they are all going towards that direction." } \\
\text { [HR Director] }\end{array}$ \\
\hline 4. Connectedness & $\begin{array}{l}\text { Being part of the society, interdependent relation- } \\
\text { ship }\end{array}$ & $\begin{array}{l}\text { "A corporation should certainly contribute to the } \\
\text { society. It is actually an interdependent relation- } \\
\text { ship, between the society and the corporation, both } \\
\text { interdependently living in harmony." [Head of a } \\
\text { Subsidiary Business] }\end{array}$ \\
\hline 5. To initiate and act & Challenging spirit & $\begin{array}{l}\text { "Something small as well—something you haven't } \\
\text { done before, but then you take the challenge and } \\
\text { act on it-I think that is the spirit of challenging." } \\
\text { [Corporate Culture Executive] }\end{array}$ \\
\hline 6. Emptiness (not to fill the vessel) & Ambiguity for interpretation & $\begin{array}{l}\text { "You don't understand what gong qi is? It is very } \\
\text { normal! It needs time to be cultivated by our corpo- } \\
\text { rate culture!" [Corporate Culture Executive] }\end{array}$ \\
\hline
\end{tabular}

interdependencies - which simultaneously constitute oneself (Ames and Rosemont 1998; Santiago 2008; Yu 1998). These virtues suggested by gong qi are inherently social and relational.

Lastly, in Chapter 28 of Daodejing, qi is described as a piece of uncarved block being shaped and sculpted; $q i$ implies the potential for what the uncarved block will become-something useful. Here, qi refers to a natural sense of virtue that can be used by the Sages to act and even govern. Although here $q i$ represents something that has become useful, it also implies the loss of simplicity during the carving and shaping.

In contrast to the modern language, ancient Chinese tends towards conciseness so that one character often represents a term, implying multi-layered meanings. For example, as the key word in the term gong qi, qi already implies the sense of belonging to the community, which gong emphasizes as being public and communal as well. As discussed in this section, it is almost impossible to fully enumerate all the aspects of being virtuous that are suggested by gong qi. The term, its ideograms and its many uses, are indicative and made tangible in irreducible thought, feeling and living. In the following section we show how this functions in SONA.

\section{How Gong Qi Functions in Organizing Virtue at SONA}

This section explores how the meanings of gong qi evolve into six main virtues of gong $q i$ and how they are implemented at SONA. The corporate motto of SONA is 'Corporation is society's gong qi' (企业是社会的公器), hence gong $q i$ is the essence of the corporate philosophy, influencing policies and practices in every SONA subsidiary across the world. The meanings presented in Table 1 are represented here in more concrete, specific usages which are evidently influencing organizational thinking and practices at SONA.

As Table 2 summarizes we identified six main virtues derived from the multi-layered meanings of gong qi in SONA. These are: (1) Being useful for society, as one of the virtues of gong $q i$, is derived from the allegorical meaning which regards gong $q i$ as a sacrificial vessel containing offerings. Its function as a containing vessel implies a sense of efficacy and its purpose for the common good; (2) Also, gong qi is seen as public goods, which cannot be obtained and should not belong to any individual. Hence, being public goods suggests a corporation should share its interests and contribute back to society; 
(3) As Mozi (Book 12, Gong Meng) argued that righteousness is the greatest $q i$ (virtue) in the world, having a sense of righteousness in the context of the society is therefore being seen as virtuous. Righteousness implies doing justice for society, with a sense of loyalty and dedication which are often advocated in Japanese corporate philosophies (Dollinger 1988); (4) Gong qi symbolizes a sacrificial vessel used in ceremonies and rituals, which indicates a deeply embedded sense of connectedness and interdependency among individuals and society, suggesting that people are inherently social. Such connectedness, as indicated in its ideograms, constitutes the gong qi; (5) $q i$ addresses the efficacy of virtue that can be used to act and even govern (Chapter 28, Daodejing). Its efficacy lies in its function and suggests such agency can be used to initiate and act; (6) As one of the key features of gong qi, the emptiness of sacrificial vessels comprises the virtue of gong qi. The vessel is intentionally not being filled, yet full of potentials and space. The inherent emptiness and inclusiveness implied by gong $q i$ are elaborated further in the Discussion section.

\section{Being Useful for Society, Producing Good Products to Solve Social Problems}

SONA's corporate motto was translated in Mandarin as 'the Corporation is to contribute to society', often promulgated by top managers such as the CEO, Mr. Dragon.

Researcher: "How do you understand the corporate motto "the Corporation is to contribute to society"'?

Mr. Dragon: "Originally in Japanese it was 'the Corporation is society's gong qi. Have you heard of the term 'gong qi'"'?

Researcher: "Yes, just wondering why it's the corporate philosophy"?

Mr. Dragon: "Essentially, what is a corporation? Just like asking what human being is. There are many answers to the question 'what is a corporation', such as, a company is for continually making profit, or doing business is for people etc. But if we conclude everything with one term, that is gong qi. Our corporation does not just belong to the shareholders, or employees, it belongs to the society. It's not just returning profit to society, but it's also about facing and solving the current problems within that society. That is one of the functions of gong qi".

[Interview with the CEO]

As the CEO of SONA China, Mr. Dragon's voice was influential. Many SONA colleagues tended to refer to Mr. Dragon, instead of SONA's founder, as the originator of the corporate motto. He kept emphasizing the profound meanings of gong qi. As a system of abstract values and management ideologies, corporate philosophy is considered very important in many organizations, especially Japanese companies (Ledford et al. 1995).

Our department is called new business department, mostly to explore the new market demand in environment protection. This is what we do. Then, what we mainly hope for, is a mission [for this department], which is located in SONA's corporate philosophy, to contribute to the society, to continuously explore social needs and satisfy them. Along with all the other SONA businesses here in China, contributing to the Chinese society, our goal is to explore other social needs. With the fast development in China, what are the new social problems, what are the new social needs? Then how we could use our advanced technology to help Chinese society to solve these problems. We started as a project team, to explore what the society really needs at the moment, what can be solved. So we are looking at areas such as health and safety, environmental protection, energy saving, and new energy.

[Interview with the Head of New Business Department]

The Head of the New Business Department emphasized the purpose of her department, as well as many SONA businesses, is being useful for society by identifying social needs, producing good products or services for the purpose of solving social problems, and thereby to make SONA a more competitive and sustainable organization. As Mr. Dragon put it, "that is one of the functions of gong qi".

\section{To Contribute to the Society, to Share Interests}

Our founder talked about the characters of gong qi. Actually, there are two parts of gong qi, one is the social side of gong $q i$, the other is the business side of gong qi. The business side of gong qi is producing good products like what I said earlier, the social part of gong $q i$ is about sharing interests, such as paying tax, making donations, and having CSR events. It is about contributing to the society. Another classical example, we have a few factories especially for employing disabled workers, to hire disabled people who would like to work.

[Interview with HR Director]

Many people in SONA referred to gong $q i$ when talking about CSR and ethics. As the core value of SONA's corporate philosophy, it seemed to have a deep influence of how the organization members think of "what a corporation should be' as a moral ideal in society. Gong qi includes the Western conceptions of CSR which consider that 
corporations have responsibilities and social obligations. Some examples are described here by the HR Director, 'paying tax, making donations, and having CSR events', and employing disabled workers who would like to work. Yet, gong $q i$ transcends these ideas of responsibility and expresses it in a fundamentally different way that employees can understand.

Our company... essentially is to contribute to the society, like the statement said. It is quite special here. [We] often clean the surroundings, [we] visit this place where mentally disabled people live... how to say it... at first it is to show the character of a company, to make people think this company is quite friendly and inclusive. Then it is to protect the environment. If you all waste resources, what are we going to do in the future? Right? If we don't care about those disabled people, leave them alone... that doesn't seem to fit... just not right. Also, if the company has already got the profit as it wants, it must make its contribution back to this society.

[Interview with a newly promoted headman of first line workers]

When talking about gong qi, people can associate the image suggested by its ideograms (of an embracive and communal vessel) as inherently part of the society. Gong qi thereby incorporates two senses of responsibility (Rämö 2011): it includes those CSR practices often seen in other MNCs such as paying taxes and charity donations (ex post); and it also affirms that corporations are essentially part of the society, with an original purpose of contributing to it (ex ante). According to the conception of gong qi, CSR is no longer an obligation that is perhaps optional for businesses; instead gong q $i$ introduces a new way of seeing the relationship between corporations and society: as an inclusive and immanent vessel of the society. Being useful for society, including making and sharing profit, is effortlessly insisted by gong $q i$ and is promulgated to everyone from top managers to production workers: Embedding its corporate philosophy extends from the morning ceremony every day, the magazines sent out to every employee, to posters on the walls of every subsidiary in the world.

\section{To Behave Righteously}

As Mozi says, "righteousness is the greatest $q i$ (virtue) in the world". Righteousness is embedded in Japanese traditional thinking and is often advocated in Japanese corporate philosophies (Dollinger 1988). It implies doing justice for the society, with a strong sense of loyalty and dedication. The importance of righteousness has been emphasized in SONA as well. The slogan "to behave righteously" often appears in internal magazines, and corporate posters in subsidiaries and factories. The HR Director described it as a 'strong belief' to do good things for the public good, as well as for the harmony between human and the nature.

Contributing to the society, to the world, we believe we can contribute towards the harmony between human and the nature. This is a strong belief. As SONA, we will never do something to ruin that; we will be righteous, do good things, and go towards the right direction. No matter what we produce, and what kind of influence we bring to the society, they are all going towards that direction.

[Interview with HR Director]

Righteousness, as one of the virtues implied by gong $q i$, is suffused into everyday practices and how people make difficult decisions. During an interview with the Head of a Subsidiary Business, she gave an example of how she would deal with stakeholder conflicts based on righteousness.

The researcher: "If different stakeholders' interests are conflicted, how would you choose?"

HoD: "Stakeholders, although they are all important, if their interests are clashing... I think we should evaluate it (the situation) according to the socially acceptable moral and ethical values, as well as the righteous value. For me the most important stakeholders are employees. They are indeed very important, because everything is done by employees. So we should treat them rightly. So, we protect their interests, offer them training and opportunities for career development."

[Interview with the Head of a Subsidiary Business]

As she put it, the righteous value is aligned with "the socially acceptable moral and ethical values", which could act as a guidance when people must make difficult decisions in SONA. Although these values and virtues remain ambiguous, when she talked about what could help in making tough decisions, she referred to the 'righteous value' as a moral guide. With hundreds of workers in the subsidiary, a sense of righteousness can guide managers like her to make justifications among various interests.

This shows how gong qi contributes an alternative perspective on ethics as it permits complexity and ambiguity when making difficult, but 'right' decisions. On one hand, it offers SONA's employees and managers moral guidance by reference to the value of righteousness. On the other hand, gong qi's inherent ambiguity (see also Point 6) calls for in situ judgement from employees and managers. Rather than providing a formulaic list from a code of ethical conduct, the righteousness implied by gong qi offers the flexibility that employees and managers could adapt to and interpret. For example, here the HoD interpreted righteousness in relation to her specific role; hence she opted to give priority 
to the employees: 'so we should treat them rightly. So, we protect their interests...' The value of righteousness lies in the fact that it is active in shaping people's ethical priorities when balancing various stakeholder interests, and both includes and transcends the use of codified values in ethical decision making. In the end, the CEO might still choose to close a subsidiary, the HoD might have to fire some employees. However, it is the indecisiveness they experienced while the righteous value implied by gong qi occurs to them that shows the efficacy of gong qi.

\section{Being Part of Society, Interdependent Relationship}

The theory of gong qi was proposed by the founder of SONA. He believed a corporation exists as one part of society. A corporation can only sustain if it has demonstrated its value for society. As a gong qi of society, a corporation is a public platform for society; it is just a part of society, a member of society.

[Interview with HR Director]

The HR Director described a corporation as merely 'a member of society', nothing more than 'a part of society'. The concept of gong qi emphasizes a sense of connectedness and calls for a new way of understanding the relationships among individuals, groups and society. It also demonstrates how a corporation is positioned as if a communal vessel that cannot be truly obtained by anyone (Daodejing, Chapter 29), which suggests a corporation does not truly belong to shareholders or top managers. Instead, a corporation is a 'public platform for society'. The development of a society relies on organizations, and an organization would not even exist without the support of society.

Why we are saying a corporation is to contribute to society. I think we are all members of society, including corporations. It's like a unit, one molecule, it exists on the foundation of society. Therefore, a corporation should certainly contribute to the society. It is actually an interdependent relationship, between the society and the corporation, both interdependently living in harmony.

[Interview with the Head of a Subsidiary Business]

This view represents another contrast to the Western mind: "because for most in the West the conscious, intentional individual is the ultimate building block of society", whereas for the East, "the individual is only a secondary effect of social relations and not the basic unit of society (Chia 2003, p. 969)." As indicated by this interdependency between corporation and society, one cannot simply exist without the other; it certainly would not sustain if it has not demonstrated its usefulness to society. Without the sense of connectedness and attending to the social relationships, such interdependencies would be lost. The virtues implied by gong qi are inherently social. It connects individuals with organizations, and immerses organizations within society; it describes a nexus of social/individual without deliberate separation.

\section{Challenging Spirit}

An aspect of usefulness to society, one reference to gong $q i$ indicates "things that can be used to act and govern" (see the last row of Table 1), like an uncarved wood block being carved into something functional. As an example of taking actions and being useful, challenging spirit is referred to as a key idea of SONA's corporate philosophy to encourage employees to take initiative and actions. The "challenging spirit' also relates to the '5S' (namely, sort, set, shine, standardize, sustain) Japanese management system (Gapp et al. 2008) which is also widely implemented in SONA. Such 'challenges' include the very small, incremental, and even slow improvements that every employee can act upon.

As one of the key points from the corporate philosophy, challenging spirit is hard to let people (in other subsidiaries) understand. A challenge is not something that has to be on the top level, so it counts as a challenge. Something small as well-something you haven't done before, but then you take the challenge and act on it-I think this is the spirit of challenging. First of all, you need to have that mentality, like a positive mindset, which is very important; then you can act on the basis of that.

[Interview with Corporate Culture Executive]

As such an embracive and inclusive notion, challenging spirit is nicely described by many participants as 'a positive mindset', a kind of 'mentality' that drives people in SONA to overcome difficulties, to take actions, to fight against the impossibilities. Such is the nature of spirit, this speaks to the essence of organizing at every level of enactment, as it is more an attitude of being, which prompts action and doing, rather than an instruction to be done.

\section{Emptiness, Intentional Absence}

From the moment of walking into SONA to the countless discussions in meeting rooms and offices, gong qi seemed everywhere and could mean many different things. The first encounter with gong qi was at the induction, where we were told it featured in the corporate motto proposed by the company's founder many years ago. Field notes of that first induction meeting record the Corporate Culture Executive saying to the researcher: 
You don't understand what gong qi is? It is very normal! It needs time to be cultivated by our corporate culture! It takes time to really understand such a deep meaningful word that our founder proposed decades ago. You need to experience that word slowly and gradually, not everyone can truly understand the meanings of that term. But our job is to let more people to understand that word. It's not easy, it's very hard, but we have to do it. You will do it with us.

[Induction Meeting, Field note]

Here gong $q i$ is identified as an essential but mysterious trope symbolizing authority on behalf of the SONA HQ in Japan. Its frequent usage did little to reveal the extent to which SONA members understood the corporate philosophy, though the ambiguity appeared to be tolerable, maybe even intentional. A new department of 'Corporate Culture' was set up to promote the concept of gong qi, but not to define it.

The translation work (we do) is part of communicating the corporate motto (gong qi), it is a necessary part. Things like that is quite difficult to be quantified, or to describe its form. It's more like a kind of spirit I think. Quite often people ask me what you guys are doing every day, it is very difficult to summarize what on earth I've been doing. I can only tell them what the actual tasks I've been doing, this and that.

[Interview with Mika, Corporate Culture Assistant]

The ambiguity of the everyday terminology is also evident in group interactions. During a meeting in 'our' Corporate Culture Department, everyone experienced an arresting moment of emptiness when Michi, the Chief of Staff of the CEO, proposed doubts of the goal of an event we were planning.

"Um... what is this for? What is the goal? Why are we planning such a big event that's going to cost a lot of money?" Michi asked.

The whole conference room went to silence.

"Encouraging our SONA spirit of challenging? I think." Someone said.

"I think nothing will be wrong if it relates with the stuff of Corporate Culture. So, we are doing this for corporate culture promotion." Another one said.

Emi considered for a moment, "then what part of the culture?"

$\ldots$

The whole room went back to silence.

[Field note]

The whole department was embarrassed by Michi's question, yet no one could give a clear and simple response even though we all knew the answer was there somewhere. It had little to do with one's capability or experience, but this episode captured the experience of emptiness with substance, the inherent difficulty to clarify the richness and the complexity. Eventually, the event was named as a 'corporate culture festival', in effect declaring to others that 'we', as the newly established 'corporate culture department', would be mainly responsible for events like this, as well as grounding its purpose in relation to 'corporate culture promotion'. Although there was an effort led by Emi to specify 'what part of the culture', the reluctance and difficulty to define corporate culture and gong qi, once again, appeared to be an almost impossible, yet necessary task. Everyone seemed to have implicitly agreed that corporate culture cannot be simply explained, and that it works better when felt and experienced by employees.

There is a sense of 'strategic ambiguity' (Christensen et al. 2013; Eisenberg 1984) that gong qi entails, which creates a sense of disruption from more instrumental thinking and encourages employees to take charge and make sense of it. The first author was part of organizing similar successful corporate activities during the fieldwork: from visiting elderly people, sweeping nearby streets on the Founder's Day, to having a staff badminton contest among SONA's subsidiaries. These efforts went beyond merely 'promoting' SONA's corporate culture as a top-down approach, which is often seen in other organizations.

As Jullien (2004, p. 93) succinctly writes, "the virtue of immanence, [it] has nothing to do with the oppositions drawn by morality, as virtue is in the sense of efficacy." In spite of the effort going into interpretation, and the recalcitrant difficulty in clarifying terms such as 'culture' and 'gong qi', it does not stop SONA members achieving the tasks effectively: "You go for the admin, I'll take care of the logistics", "if it's something to do with culture, shall we prepare some corporate philosophy materials?". Everything seemed to be running perfectly in the SONA machine, every moment full up with meaningful activity... Until a voice comes in from outside: "Um... what is this for? What is the goal?"

This is one of the most unforgettable moments in SONA, a moment in which self-evident meaningfulness of activity seems to evaporate, leaving an emptiness which makes us question the seemingly obvious but hard to clarify terms in organizations. Gong qi appears to be a representation of intentional ambiguity and allows this experience of immanence when buried in the fullness of everyday tasks-a communal (and inclusive) vessel elaborately decorated on the outside, composing its essential and necessary emptiness. ${ }^{2}$

\footnotetext{
${ }^{2}$ It is perhaps worth acknowledging here that a more traditionally critical reading of this example might approach it as a fracture in a totalizing corporate discourse. That would be to locate the interpretation in an intellectual tradition derived broadly from the Frankfurt school, Marxist dialectics and Foucauldian studies of power relations. However, Daoism speaks directly of experiencing meaninglessness and emptiness, lauding the opportunity to sense 'life', the 'Way' beyond 'system'.
} 
This section has presented findings to show how gong $q i$ is interpreted in SONA and the practices that express the belief that the corporation should be an inherently virtuous gong qi for society. The analysis of gong qi evokes perspectives on inclusiveness and emptiness, of form and flow, and speaks to contemporary organizing experience as well as hoped for futures. Gong qi's inclusiveness is seen through the various virtues implied by the rich meanings of the term, contrasted with the ambiguous interpretations and intentional absence experienced and expressed by employees at SONA. Both inclusiveness and emptiness are embedded within classical philosophies. They are not static, bipolar distinctions, but feature as two intrinsically paradoxical and interdependent potentials. Gong qi (as perhaps a communal vessel) contains many aspects that are obscure and insubstantial, which transpires to be valuable because the emptiness provides the ambiguous space to be embracive, allowing local interpretation and situational adaptation.

\section{Discussion}

We have discussed that endogenous conceptions and theory from non-Anglophone contexts are particularly needed due to their distinctive philosophical traditions and cultural contexts. This study illustrates how gong $q i$, as an endogenous metaphor for corporation, functions in organizing virtues in a Japanese MNC in China. Adopting a qualitative and ethnographic approach to this research inquiry, we have offered findings in the previous section. In conclusion to this, we demonstrate the value of endogenous concepts such as gong $q i$ in extending our understanding of a corporation as an inclusive and virtuous social entity, together with the elusive, implicit, and forever evolving nature of organizational life that is rarely noticed.

We suggest that the virtuous qualities of gong qi make it particularly well suited to the discussion of business ethics and organization. The inclusiveness and emptiness of gong $q i$ broaden our understanding of ethics and organization as embedded within philosophical traditions in China and Japan, but also contributing to the debate on Eastern/Western ways of thinking (e.g. Chia 2003; Jullien 2004; Koehn 2013). Through gong qi, our understanding towards virtue is extended beyond morality and the often simplified fixation on what things should be; rather, it suggests the possibilities for intuitive exploration and adaptions to emerge in situ, which might never be realized if one were only to follow rational assessment and clear objectives (Chia and Holt 2009). The metaphor of gong qi interrupts the conventional responses, and opens the space for situational configuration, which allows us to see the virtue of immanence, the beauty of implicitness, and the efficacy of gong qi. We argue some ways in which this supplements and challenges extant ethical concepts through the notion of gong qi, which on the one hand, serves to construct shared meaning and social order; yet on the other hand demonstrates the merit of emptinessan experience of appreciating potentiality, elusiveness, and indeterminacy. This, we suggest, is a seldom-recognized perspective that is novel from the West and becomes evident in this Sino-Japanese context.

One evident function of semantic ambiguity is an escape from discourse and space. When facing the highly complex, ambiguous, and chaotic business environment, contrasted with operational requirements for specificity and measurement, concepts like gong $q i$ can help organizations and individuals acknowledge their not-knowing and not-believing (Chia 2003; Crossman and Doshi 2015). Gong qi is a symbolic container for the emptiness that people experience. This 'not-knowing' almost acts as the designed ambiguity that draws people in, seeking meaning - though it may also suck them under (Kunda 1992). As Tsoukas (1998) argues, ambiguity does not indicate the absence of organizing; the emptiness rarely implies void. If it can be tolerated, it opens up a possibility for indeterministic thinking, and hence gong $q i$ acts as a vessel for creativity, though it creates nothing itself.

As part of SONA corporate language (Llewellyn and Harrison 2006; Watson 1994), gong qi was introduced to SONA's Chinese subsidiaries as a 'Japanese' term. ${ }^{3}$ It was embedded in induction training programs, and signifies the character of SONA that one needs to learn in order to belong. Unlike other terms much used in SONA, such as 'maximization' (最大化), gong qi can almost always be found in the narrative of current events or SONA culture and histories. Mr. Dragon, the CEO often played the part of the storyteller: not just informing employees why SONA should be gong qi, but 'motivating' (Christensen et al. 2013; Thyssen 2003) them by imagining this virtuous vessel (corporation) serving for society. Thus, gong $q i$ is interpreted by organizational members as the key concept that can guide but not confine them in everyday practices, and help them motivate others.

As discussed previously, gong $q i$ is also being practiced as ' $l i$ ' (礼), the core of the organizational ritual. Together with other corporate mottos, gong qi is chanted at morning ceremonies in every subsidiary of SONA in the world. A variety of corporate events, just like the SONA festival, are making every effort to reiterate associations to gong qi.

\footnotetext{
${ }^{3}$ As the characters of gong qi (公器) remain the same in Chinese and Japanese, gong qi was introduced from SONA's headquarter to overseas subsidiaries as a 'Japanese' term. Through our fieldwork, we gradually realized the ideograms and meanings come from classical Chinese philosophies, which are assimilated in Japanese philosophical traditions. Hence, we do not intend to label gong qi as simply 'Chinese' or 'Japanese' but converged as a non-Anglophone concept.
} 
From generation to generation, SONA's current and ancestral leaders relentlessly present $g o n g ~ q i$ as this almost sacred vessel through which to express responsibility for the people, environment and the community. As a virtuous corporation, gong $q i$ is believed to contain the promises made to SONA employees, enabling it to live up to various social obligations, and to influence other stakeholders.

However, this is not a universally successful function. As presented in item 6 above, 'Emptiness, intentional absence', the example from fieldnotes describes a quiet and sudden moment contrasting with the ordinarily busy and fulfilling everyday life (Goffman 1959). This contrast shows how the ambiguity of ethical concepts like gong qi creates a temporary rupture in organizational routine. This is a precious moment that we should not simply ignore, nor treat only as a failure or weakness of ethics. To wonder what on earth we are doing, what is the goal, is a profoundly ethical event. To constantly re-consider 'what matters'-including which virtues matter, and what it is about them that matters, in which contexts-is the basis of the Aristotelian virtue of phronesis (see Shotter and Tsoukas 2014). But the persistence of an equivocal idea at the heart of a corporate philosophy suggests that the quality of semantic elusiveness is an important and praised quality. Gong $q i$ is so highly valued because it is mysterious, and impalpable; the attempt to grasp it merely evokes an experience of no-meaning, the substance beneath emptiness.

The sense of emptiness with substance is recognized in classical philosophies. As put by Laozi (or Lao-Tzu), "you find within it the space, that makes a vessel as a vessel" (Chapter 11, 2008 [c. 500 BCE], p. 27). Emptiness is a manifestation of ' $X u$ ' (虚), an elusive Daoist concept, which “creates a unique ecological space of metamorphosis that nourishes mutual becoming" (Yu 2016, p. 93). The emptiness evokes nourishment and awakening. It encourages oneself to explore the hidden meaning, the unnamable, indeterminate, indefinable Daoist virtue: to attend to the substance of absence, the sound of tranquility, the taste of blandness, the shape of the invisible, and the meaning of the ineffable.

Also, the challenge for MNCs to implement CSR strategies and ethical practices to overseas subsidiaries is recognized, particularly in the consideration of how well it would work for headquarter-based policies to be implemented to local subsidiaries (see Acquier et al. 2018). The elusiveness of gong qi suggests that rather than applying a clearly-defined and pre-fixed ethical concept, the intentional ambiguity of notions like gong qi offers potential and encouragement for local interpretations and practical adaptations. Such 'strategic ambiguity' (Christensen et al. 2013; Eisenberg 1984) functions in ethical discourses and practices in organizations because it enables gong qi to be adapted to various industrial sectors, engage with diverse stakeholders, span organizational boundaries, and prompt employees to relate it to their everyday tasks. This seems similar to notions of empowerment sometimes advocated in Western management theories and practices (e.g. Conger and Kanungo 1988). Yet, instead of developing empowerment as a separate managerial strategy, gong qi permeates and forges together various managerial activities such as planning, organizing, commanding, co-ordinating and controlling (Fayol 1949), as if they were never apart. Hence, the empowerment of employees could occur effortlessly and almost without being noticed. Different to most Western managerial perspectives, this is the efficacy of gong qi. As in SONA, the ineffable and somewhat mysterious notion of gong qi has attracted people's interest, invited them to interpret this concept in their everyday practices, and contributed to social harmony.

To summarize the argument in this discussion section, we suggest gong $q i$ exemplifies a profound understanding of business ethics from a non-Western context. Rather than considering virtue as a list of demonstrable individual qualities, gong qi contributes to a perspective of virtue and organization that is constituted by its elusiveness, inclusiveness, and immanence. Furthermore, as an endogenous metaphor, gong $q i$ allegorically symbolizes a communal and sacred vessel that is used in rituals connecting a generation to its ancestors-an experience of both absence and presence. Gong $q i$ is valued especially because the presence of the vessel evokes emptiness that makes it a grandiose vessel. Its emptiness is its defining virtue; the ability to experience emptiness is praised in Daoism; likewise, the perception of no-meaning, of unconditioned 'is-ness'. Gong qi brings indeterminacy and inexpressibility into our perception as a stepping stone to grasp the complex and implicit organizational life.

\section{Managerial Implications and Future Research}

We suggest gong qi can be applied beyond SONA as a metaphor through which to explore various interpretations of what a corporation is in relation to society. As discussed previously, the universal adaptation of Western-inspired ethical concepts and theories to non-Anglophone contexts is problematic as they do not necessarily take deeply embedded philosophical traditions and cultural values into consideration (e.g. Todeschini 2011; Wang and Juslin 2009). In the same vein, we do not argue the universal applicability for the notion of gong qi without considering the cultural and organizational contexts. Gong qi, rooted in Chinese (and Japanese) classical philosophies, can potentially appeal to organizations in societies that share similar philosophical traditions, such as China, Japan, Korea, Singapore, and other parts of East Asia. We do not imply that every corporation in 
Table 3 The potential managerial applications of gong $q i$

\begin{tabular}{ll}
\hline Virtues of gong qi & Potential managerial applications of gong qi \\
\hline 1. Being useful for society & $\begin{array}{l}\text { To identify the current and potential social needs in relation to its business; } \\
\text { To produce products and provide services to solve the identified social problems } \\
\text { To conduct the usual CSR practices, such as paying tax, making donations, employing people with disabilities; } \\
\text { To align its organizational purpose as inherently contributing to society } \\
\text { 2. To share with others }\end{array}$ \\
$\begin{array}{l}\text { To introduce the value of righteousness to employees; } \\
\text { 3. Righteousness }\end{array}$ & $\begin{array}{l}\text { To explain it is a deeply connected and interdependent relationship between the society and the corporation; } \\
\text { To align the goals for organizations and society toward the common good }\end{array}$ \\
4. Connectedness & $\begin{array}{l}\text { To encourage employees to take initiatives in the organization and positive actions; } \\
\text { To motivate employees to overcome challenges and adapt to change }\end{array}$ \\
5. To initiate and act & $\begin{array}{l}\text { To maintain a sense of strategic ambiguity and leave room for various interpretations of gong qi in different } \\
\text { contexts; }\end{array}$ \\
6. Emptiness, ambiguity for \\
interpretation
\end{tabular}

the geographic region of China and Japan would automatically be suitable for a corporate philosophy of gong qi. There would have to be some consonance with the ambitions, values and products of the organization that provide potential foundations for gong $q i$.

Nevertheless, we suggest that the term gong qi can offer potential managerial implications for other organizations. Those working with colleagues who share a Sino-Japanese heritage will find that gong qi resonates in a more integrative way than the relatively dry abstractions of 'CSR' or 'corporate mission'. The forgoing discussion has enumerated some of the depth and subtleties of this cultural resonance. If applied with due care and sensitivity, gong qi is likely to have a significantly beneficial effect on employee engagement, shared purpose and a common ethical reference point when making difficult decisions. For example, MNCs like SONA operate in many countries across different industries. Its strategic ambiguity offers the flexibility to embed gong qi into their corporate philosophies and to rediscover purposes that are suitable for the corresponding industries and local organizational contexts.

In practice it is important to let employees and relevant stakeholders understand and start to interpret the elusive meanings that gong qi evokes. This was the aim of the global work from SONA's Corporate Culture Department, which included various internal communications and external engagement activities, explaining the concept via corporate posters and magazines, expressing the allegorical meanings through managers' speeches, holding festivals and having other staff and community events for the common good, and so on. These are familiar to many HR functions and as ever, the impact of such activities depends on the efficacy of the underlying values. The deeply embedded philosophical roots, inclusiveness and emptiness of gong qi are an advantage in this regard.
Interestingly, on further enquiry we found that gong $q i$ features in the corporate philosophies of other Japanese MNCs as well, for example Honda and Panasonic. Mr. Konosuke Matsushita (松下幸之助), the late founder of Panasonic, declares that the future of gong qi management is approaching, it is crucial to understand that companies are inherently public institutions of society (Mizukami 2014; Panasonic 2018). This growing usage of gong qi suggests that our findings may be generalized with caution.

The potential managerial applications of gong qi are suggested in Table 3. As discussed previously, we recognize the importance of context. Hence, this list of gong qi's applications is merely suggestive, such as for managers working in similar cultural and organizational contexts. As the main purpose of this article is to introduce the meanings of gong $q i$ and exemplify how it is implemented in SONA, we do not limit gong qi's applications to these aspects as shown in Table 3. Future research can provide more specific stepby-step guidance on how to incorporate gong qi in different organizational contexts. Where an organization adopts gong $q i$ as the central motif of its philosophy and values, we might expect to see them engage in activities that give expression to each of the six aspects of virtues enumerated in Table 3. To be clear, undertaking these activities in themselves does not constitute virtue; but they are ways in which the presence of gong qi may be realized in organizational life.

Organizations in English-speaking countries can also possibly apply gong $q i$ as a foreign, mysterious, yet embracive concept. Gong $q i$, as exemplified in SONA, can work at the core of a corporate philosophy, as well as complementing other values as a useful metaphor. In the same vein, gong $q i$ can be applied in either private sector or public sector organizations, with its strong emphasis on 'public goods' that inherently belong to and enhance the society. A 'light touch' reference to gong qi could be especially useful in communicating corporate values and building trust with 
Chinese and Japanese suppliers, partners, regulators or customers.

Gong qi contributes to strategy practices in ways that are distinct from the 'planning and positioning' approaches that are more commonly taught (if not practised) in Western firms. While the latter tend to construct the firm as an agent that actively positions itself in relation to other actors in its industry (its suppliers, customers etc.) and wider society, companies that are guided by gong qi conceive themselves as integral to society, seeking to play their part almost as 'organs' within a connected and organic whole (see Fig. 1 for gong qi's ideograms).

Future research in other Eastern, Southern and nonAnglophone contexts, as well as historically heterodox contexts could further develop the understandings and widen implications of gong qi: for example, to trace its influence through religious and political movements. It may also be fruitful to consider what we would find if we took gong $q i$ (rather than ethics as generally understood) as a starting point for inquiry into different forms of organizations and also different industrial sectors. Would it offer a differentmore positive-appreciation of ambiguity, uncertainty and humility? It could also be valuable to study this in other subsidiaries of MNCs (like SONA) which are in other parts of the world. For instance, further research can be conducted to examine to what extent gong $q i$ has potentially changed behaviors and adjusted in subsidiaries in distinctively Anglophone contexts such as the US or UK.

\section{Conclusion}

This article contributes (a) an embracive yet immanent perspective of understanding ethics and organization, derived from the endogenous concept gong $q i$, as an inclusive and empty vessel rooted in non-Anglophone classical philosophies; and (b) an empirical study to exemplify how gong qi, as a metaphor for corporation with multi-layered meanings, is interpreted and practiced in a Japanese MNC at China. As a moral ideal of corporations in society, gong qi serves to construct shared and embracive meanings, yet it remains indefinable and unnamable in the mundanity of everyday life. In this way, it provides a powerful metaphor which suffuses a new way of seeing and thinking about business ethics and organization.

Methodological choices have implications that may limit this study in particular ways. For instance, the first author's personal interests and identity inevitably influenced the construction of the ethnographic account and we endeavored to be aware of this. The fieldwork was conducted in the "Corporate Culture Department' where the discussions of gong $q i$ were openly expressed, and its analysis is the outcome of many hours of engagement with and immersion in the data.
It is proffered here as a well-considered, reflective account of how gong qi is interpreted and practiced in everyday life in MNCs like SONA.

In concluding, we offer an empirical contribution of how an endogenous concept of gong $q i$ has been interpreted and practiced in a non-Anglophone organization context, as well as how gong $q i$ affords an insight into the elusive, implicit and complex nature of organizational realities. Rather than ignoring the cultural context or imposing a comparative scale drawn from Western-based studies, we stress the potentiality of endogenous approaches in exploring cultural understandings that are constructed and embedded in everyday life. As an example of ethical concepts, gong qi cannot be understood as a list of inherent virtues, but it allegorically represents a moral ideal of what a corporation should be in society, and how people in and around the corporation attend to their social relations and responsibilities. Gong qi, as an inclusive and empty vessel, contributes to an embracive but immanent perspective that calls for a new way of understanding the ineffability of organizational life. Thus, we propose that notions of virtue, like those suggested by gong qi, evoke profound meanings that should not be taken for granted or taken out of context. Instead, they may be fruitfully explored through endogenous approaches that illuminate their cultural and philosophical interpretations and broaden our understanding of ethics and organization.

\section{Compliance with Ethical Standards}

Conflict of interest The authors declare that they have no conflict of interest.

Ethical Approval All procedures performed in studies involving human participants were in accordance with the ethical standards of the institutional and/or national research committee and with the 1964 Helsinki declaration and its later amendments or comparable ethical standards.

Informed Consent Informed consent was obtained from all individual participants included in the study.

Open Access This article is distributed under the terms of the Creative Commons Attribution 4.0 International License (http://creativeco mmons.org/licenses/by/4.0/), which permits unrestricted use, distribution, and reproduction in any medium, provided you give appropriate credit to the original author(s) and the source, provide a link to the Creative Commons license, and indicate if changes were made.

\section{References}

Acquier, A., Carbone, V., \& Moatti, V. (2018). “Teaching the Sushi Chef": Hybridization work and CSR integration in a Japanese Multinational Company. Journal of Business Ethics, 148(3), 625-645. 
Alzola, M. (2015). Virtuous persons and virtuous actions in business ethics and organizational research. Business Ethics Quarterly, 25(3), 287-318.

Alzola, M., Romar, E.J., and Hennig, A. (2017). Call for papers: Virtue ethics between east and west. Journal of Business Ethics.

Ames, R. T., \& Rosemont, J. (1998). The analects of confucius: A philosophical translation. New York: Random House Publishing Group.

Berger, P., \& Luckmann, T. (1966). The social construction of reality: A treatise in the sociology of knowledge. New York: Doubleday \& Company Inc.

Boardman, C. M., \& Kato, H. K. (2003). The confucian roots of business Kyosei. Journal of Business Ethics, 48(4), 317-333.

Briggs, J. (2005). The use of indigenous knowledge in development: Problems and challenges. Progress in Development Studies, 5(2), 99-114.

Chan, G. K. Y. (2008). The relevance and value of confucianism in contemporary business ethics. Journal of Business Ethics, $77(3), 347-360$.

Chia, R. (2003). From knowledge-creation to the perfecting of action: Tao, Basho and pure experience as the ultimate ground of knowing. Human Relations, 56(8), 953-981.

Chia, R., \& Holt, R. (2009). Strategy without design: The silent efficacy of indirect action. Cambridge: Cambridge University Press.

Christensen, L. T., Morsing, M., \& Thyssen, O. (2013). CSR as aspirational talk. Organization, 20(3), 372-393.

Chun, R. (2005). Ethical character and virtue of organizations: An empirical assessment and strategic implications. Journal of Business Ethics, 57(3), 269-284.

Confucius. (1979 [c. 500-400 BCE]). The Analects 论语. (trans: Lau, DC.) London: Penguin Books

Conger, J. A., \& Kanungo, R. N. (1988). The empowerment process: Integrating theory and practice. Academy of Management Review, 13(3), 471-482.

Crossman, J., \& Doshi, V. (2015). When not knowing is a virtue: A business ethics perspective. Journal of Business Ethics, 131(1), $1-8$.

Dai, W. (2018). Chinese thinking and a Daoist alternative origin of organizing. In T. Peltonen, H. Gaggiotti, \& P. Case (Eds.), Origins of organizing (pp. 114-128). Cheltenham: Edward Elgar Publishing.

Dei, G. J. (1993). Sustainable development in the African context: Revisiting some theoretical and methodological issues. African Development, 18(2), 97-110.

Denzin, N., \& Lincoln, Y. S. (2005). Introduction: The displine and practice of qualitative research. In N. Denzin \& Y. Lincoln (Eds.), The sage handbook of qualitative research (3rd ed., pp. 1-32). London: Sage.

Dollinger, M. J. (1988). Confucian ethics and Japanese management practices. Journal of Business Ethics, 7(8), 575-584.

Du, X. (2015). Does Confucianism reduce minority shareholder expropriation? Evidence from China. Journal of Business Ethics, 132(4), 661-716.

Eisenberg, E. M. (1984). Ambiguity as strategy in organizational communication. Communication Monographs, 51(3), 227-242.

Endo, T., Delbridge, R., \& Morris, J. (2015). Does Japan still matter? Past tendencies and future opportunities in the study of Japanese firms. International Journal of Management Reviews, $17(1), 101-123$.

Fayol, H. (1949). General and industrial management. London: Pitman Publishing.

Flick, U. (2002). An introduction to qualitative research. London: Sage.
Gapp, R., Fisher, R., \& Kobayashi, K. (2008). Implementing 5S within a Japanese context: An integrated management system. Management Decision, 46(3-4), 565-579.

Goffman, E. (1959). The presentation of self in everyday life. London: Penguin Books.

Hennig, A. (2016). Three different approaches to virtue in businessAristotle, Confucius, and Lao Zi. Frontiers of Philosophy in China, 11(4), 556-586.

Hofstede, G., \& Bond, M. H. (1988). The confucius connection: From cultural roots to economic growth. Organizational Dynamics, 16(4), 5-21.

Humphreys, M., Brown, A., \& Hatch, M. J. (2003). Is ethnography jazz? Organization, 10(1), 5-31.

Humphreys, M., \& Watson, T. (2009). Ethnographic practices: From 'Writing-up Ethnographic Research' To 'Writing Ethnography'. In S. Ybema, D. Yanow, H. Wels, et al. (Eds.), Organizational ethnography: Studying the complexities of everyday orgazational life (pp. 40-55). London: Sage.

Jackson, T. (2013). Reconstructing the indigenous in African management research. Management International Review, 53(1), $13-38$

Jackson, T. (2014). Cross-cultural management from the South: What a difference global dynamics make. International Journal of Cross Cultural Management, 14(1), 3-5.

Jullien, F. (2004). A treatise on efficacy: Between Western and Chinese thinking (trans: Lloyd, J.). Honolulu: University of Hawai'i Press.

Karam, C. M., \& Jamali, D. (2017). A cross-cultural and feminist perspective on CSR in developing countries: Uncovering latent power dynamics. Journal of Business Ethics, 142(3), 461-477.

Kimura, T., \& Nishikawa, M. (2018). Ethical leadership and its cultural and institutional context: An empirical study in Japan. Journal of Business Ethics, 151(3), 707-724.

Koehn, D. (2013). East meets west: Toward a universal ethic of virtue for global business. Journal of Business Ethics, 116(4), 703-715.

Koehn, D. (2016). Non-Western virtue ethics, commerce and the common good. In K. Akrivou \& A. Sison (Eds.), The challenges of capitalism for virtue ethics and the common good: Interdisciplinary perspectives (pp. 272-282). Cheltenham: Edward Elgar Publishing.

Kunda, G. (1992). Engineering culture: Control and commitment in a high-tech corporation. Philadelphia: Temple University Press.

Lao-Tzu(老子). (2008 [c. 500 BCE]). The Book of Tao and Teh (With the Bamboo Slip-text: “The Great One Begot Water”) 道德经( 附楚简《太一生水》). (trans: Gu, Z.). Beijing: China Foreign Languages Press.

Ledford, G. E., Wendenhof, J. R., \& Strahley, J. T. (1995). Realizing a corporate philosophy. Organizational Dynamics, 23(3), 5-19.

Li, P. P., Leung, K., Chen, C. C., et al. (2012). Indigenous research on Chinese management: What and how. Management and Organization Review, 8(1), 7-24.

Lin, L.-H., Ho, Y.-L., \& Lin, W.-H. E. (2013). Confucian and Taoist work values: An exploratory study of the Chinese transformational leadership behavior. Journal of Business Ethics, 113(1), 91-103.

Llewellyn, N., \& Harrison, A. (2006). Resisting corporate communications: Insights into folk linguistics. Human Relations, 59(4), $567-596$.

Lockett, M. (1988). Culture and the problems of Chinese management. Organization Studies, 9(4), 475-496.

Low, K. C. P., \& Ang, S. L. (2012). Confucian leadership and corporate social responsibility (CSR), the way forward. Journal of Business Research, 2(1), 85-101.

$\mathrm{Lu}$, X. (1997). Business ethics in China. Journal of Business Ethics, 16(14), 1509-1518 
Ma, L., \& Tsui, A. S. (2015). Traditional Chinese philosophies and contemporary leadership. The Leadership Quarterly, 26(1), $13-24$.

Maruyama, M. (1981). Endogenous research: Rationale. In P. Reason \& J. Rowan (Eds.), Human inquiry: A sourcebook for new paradigm research. Chichester: Wiley.

McAuley, J. (2004). Hermeneutic understanding. In C. Cassell \& G. Symon (Eds.), Essential guide to qualitative methods in organizational research (pp. 192-202). London: Sage.

McElhatton, E., \& Jackson, B. (2012). Paradox in harmony: Formulating a Chinese model of leadership. Leadership, 8(4), 441-461.

Mitra, R. (2012). "My country's future": A culture-centered interrogation of corporate social responsibility in India. Journal of Business Ethics, 106(2), 131-147.

Mizukami, T. (2014).「公器の経営2.0」の時代がやってきた (The “management of gong qi 2.0" era has came). https://bizgate.nikke i.co.jp/article/DGXMZO2856747026032018000000?chann $\mathrm{el}=\mathrm{DF} 260320183652$.

Morgan, G. (1986). Images of organization. London: SAGE.

Morgan, G. (2016). Commentary: Beyond Morgan's eight metaphors. Human Relations, 69(4), 1029-1042.

Ong, W. J. (1967). The presence of the word: Some prolegomena for cultural and religious history. New Haven and London: Yale University Press.

Ornatowski, G. K. (1999). Confucian values, Japanese economic development, and the creation of a Modern Japanese Business Ethics. In G. Enderle (Ed.), International business ethics: Challenges and approaches (p. 386). Notre Dame: University of Notre Dame Press.

Panasonic. (2018). CSR: Compliance (Corporate Ethics). https://is-c. panasonic.co.jp/en/csr/compliance/.

Rämö, H. (2011). Visualizing the phronetic organization: The case of photographs in CSR reports. Journal of Business Ethics, 104(3), 371-387.

Romar, E. J. (2002). Virtue is good business: Confucianism as a practical business ethics. Journal of Business Ethics, 38(1-2), 119-131.

Santiago J. (2008). Confucian ethics in the analects as virtue ethics. Philosophical Ideas and Artistic Pursuits in the Traditions of Asia and the West: An NEH Faculty Humanities Workshop.

Schuler, R. S., Dowling, P. J., \& De Cieri, H. (1993). An integrative framework of strategic international human resource management. Journal of Management, 19(2), 419-459.

Shotter, J., \& Tsoukas, H. (2014). Performing phronesis: On the way to engaged judgment. Management Learning, 45(4), 377-396.
Thyssen, O. (2003). Values-the necessary Illusions. In M. Morsing \& C. Thyssen (Eds.), Corporate values and responsibility. The Case of Denmark (pp. 163-178). Copenhagen: Samfundslitteratur.

Todeschini, M. M. (2011). "Webs of engagement": Managerial responsibility in a Japanese company. Journal of Business Ethics, 101(Suppl 1), 45-59.

Tsoukas, H. (1998). Introduction: Chaos, complexity and organization theory. Organization, 5(3), 291-313.

Tsui, A. S. (2009). Autonomy of inquiry: Shaping the future of emerging scientific communities. Management and Organization Review, 5(1), 1-14.

Tu, W. (1998). Humanity and self-cultivation: Essays in Confucian thought. Boston, MA: Cheng \& Tsui Company.

Wang, C. L., \& Lin, X. (2009). Migration of Chinese consumption values: Traditions, modernization, and cultural renaissance. Journal of Business Ethics, 88(Suppl 3), 399-409.

Wang, L., \& Juslin, H. (2009). The impact of Chinese culture on corporate social responsibility: The Harmony approach. Journal of Business Ethics, 88(3), 433-451.

Watson, T. (1994). In search of management: Culture. Chaos and control in managerial work. London: Routledge.

Watson, T. (2011). Ethnography, reality, and truth: The vital need for studies of 'How things work' in organizations and management. Journal of Management Studies, 48(1), 202-217.

Xu, S., \& Tang, K. (2018). Shuo Wen Jie Zi 说文解字. Beijing: Zhonghua Book.

Xu, S., \& Yang, R. (2010). Indigenous characteristics of Chinese corporate social responsibility conceptual paradigm. Journal of Business Ethics, 93(2), 321-333.

Ybema, S., Yanow, D., Wels, H., et al. (2009). Studying everyday organizational life. In S. Ybema, D. Yanow, H. Wels, et al. (Eds.), Organizational ethnography: Studying the complexities of everyday organizational Life (pp. 1-20). London: Sage.

Yin, J., \& Quazi, A. (2018). Business ethics in the greater China region: Past, present, and future research. Journal of Business Ethics, 150(3), 815-835.

Yu, J. (1998). Virtue: Confucius and aristotle. Philosophy East and West, 48(2), 323-347.

Yu, P. (2016). Zones of indeterminacy: Art, body and politics in Daoist thought. Theory, Culture \& Society, 33(1), 93-114.

Zhuangzi. (350-250 BCE). Tianyun 天运. https://ctext.org/zhuangzi/ revolution-of-heaven/zhs.

Publisher's Note Springer Nature remains neutral with regard to jurisdictional claims in published maps and institutional affiliations. 